\title{
Educación artística en museos: sinergia entre aula y museo. Actualidad y desafíos en la construcción de una alianza ${ }^{1}$
}

\author{
Natalia Miralles Jara ${ }^{2}$ \\ Universidad Alberto Hurtado, Stgo. de Chile, Chile \\ nmiralles@uahurtado.cl
}

1 Artículo de reflexión.

2 Doctora en educación artística. Académica, Departamento de Arte de la UAH. 


\title{
Educación artística en museos: sinergia entre aula y museo. Actualidad y desafíos en la construcción de una alianza
}

\section{Resumen:}

El aumento de la oferta educativa en los museos de arte ha sido considerable a partir de la década de los 90 , encontrándonos en un escenario favorable para el desarrollo de la educación artística en el ámbito no formal; sin embargo, y de forma paralela, podemos ver como la asignatura de educación artística se encuentra en una situación precaria en el currículum escolar. Dentro de este marco, surge la importancia de investigar respecto a cómo generar una alianza entre museo y escuela que permita fortalecer el área artística.

El siguiente trabajo indaga sobre los enfoques actuales que museos de arte, en el ámbito chileno y de otros países de la región, han generado con el fin de optimizar la relación con los docentes. Además, revisa las estrategias y materiales didácticos creados para este fin.

Palabras clave: Museos, arte, educación artística, docentes.

\section{Artistic education in museums. Synergy between classroom and museum, current importance and challenges in theconstruction of an alliance}

\begin{abstract}
The increase of the educative supply in the art museums has been considerable since the decade of the 90', locating us in a favorable scenario for the development of the artistic education in the non-formal area; nevertheless, and in a parallel way, we can see how the course of artistic formation is found in a precarious situation inside the scholar curriculum. Within this frame, it emerges the importance of researching about how to generate an alliance between museum and school that allows to strengthen the artistic field.

The following article inquiries about the current focus that art museums, in Chile and other countries of the region, have generated in order to optimize the relation with the teachers. Also, the strategies and didactic resources created for this end are reviewed.
\end{abstract}

Keywords: museums, art, education, art course, teachers.

\section{Educação artística em museus: sinergia entre sala e museu. Atualidade e desafios na construção de uma aliança}

\section{Resumo}

O aumento da oferta educativa nos museus de arte tem sido considerável a partir dos anos 90, encontramo-nos em um ambiente favorável para o desenvolvimento da educação artística no contexto de educação não formal; no entanto, e em paralelo, podemos ver como o áreas da educação artística em uma situação precária no currículo escolar. Neste contexto, a importância da investigação da idea de como construir uma parceria entre museu e escola que vai reforçar a área artística.

$\mathrm{O}$ artigo explora abordagens atuais para museus de arte na área chilena e outra países da região têm gerado, a fim de otimizar o relacionamento com os professores. Além disso, a revisão das estratégias e materiais de ensino criado para esta finalidade.

Palavras-chave: museus, arte, educação artistica, professores de arte-educação. 


\section{Museo y escuela. Orígenes comunes}

Museos y escuelas son instituciones que tienen en común numerosas problemáticas porque ambas nacieron en el contexto de la Modernidad. Éstas fueron tomadas como agentes relevantes para afianzar los ideales de aquella época. En sus inicios, museo y escuela conciben a la educación de una forma similar. En estas instituciones el receptor cumple un rol pasivo, limitado a la adquisición de conocimientos seleccionados por expertos.

A fines del siglo xIx, el museo y la escuela se distancian en aspectos metodológicos, pues para el primero la prioridad pasó a ser la colección, lo que provocó el surgimiento del concepto de museo guardián. En este concepto, el objeto que se custodia tiene mayor importancia que los visitantes. De esta forma, se desarrolló la función conservadora e investigativa del museo que, a su vez, le dio poca importancia al ámbito educativo.

Esta prioridad se mantuvo durante mucho tiempo, pues existieron algunos museos que de forma muy tardía se sumaron al nuevo paradigma que emerge con fuerza durante la segunda mitad del siglo xx, y que vuelve a poner la educación en un lugar central.

Desde esta época y específicamente con posterioridad a la creación del ICOM, los museos comenzaron a reflexionar sobre su aporte como eventuales agentes educativos en el ámbito no formal, aspecto que permitió el paso de un museo guardián a un museo concebido como institución educativa y cultural.

La tendencia que centra su atención en la formación de las personas por encima del cuidado y vigilancia de los objetos se Ilama nueva museología. Ésta sienta sus bases en Latinoamérica gracias a la Mesa de Santiago realizada en Chile en 1972, al instaurar un cambio radical en la visión de los museos, considerándolos como espacios pensados para la comunidad. Esto permitió constituir el paradigma de concebir al patrimonio como un instrumento de desarrollo social.

El caso de la escuela es similar, actualmente se habla de una nueva crisis de ésta, gatillada desde los años 70 por el explosivo avance de los medios de comunicación y la tecnología que la han alejado de su sitial monopólico de trasmisión del conocimiento. Así mismo, se han realizado fuertes críticas respecto al énfasis que los países de la región ponen en determinadas asignaturas con el fin de mejorar resultados en las pruebas estandarizadas en desmedro de otras áreas del currículum, particularmente las artísticas.

Ambas instituciones se ven actualmente exigidas a continuar por la senda de la renovación de sus esquemas. Esto es muy interesante, ya que les otorga posibilidades 
de hacer cambios sustanciales a la hora de enfrentar su tarea como agentes educadores.

En el caso de la educación artística también hubo un cambio de paradigma a fines del siglo xx, pues emergieron nuevos enfoques que otorgan mayor importancia a la apreciación, la experiencia estética y la inclusión de los campos de la cultura visual. Estos aspectos han generado nuevas propuestas que resaltan la importancia del trabajo entre docentes de arte, museos e instituciones culturales.

Sumado a esto, se instala desde hace algunos años en el campo del arte, el concepto de giro educativo, tendencia que según Carmen Mörsch (2012) logró ser gravitante a la hora de conectar el campo curatorial del arte con las pedagogías emancipadoras. Lo anterior, implica un acercamiento entre posturas curatoriales y educativas con el fin de generar aproximaciones críticas en los contextos institucionales del arte; por ejemplo, la incorporación y realización de proyectos educativos bienales de Mercosur en Latinoamérica ha sido fundamental desde su primera edición en 1997 al realizar programas educativos, los cuales adquieren mayor notoriedad a partir del giro educativo que toma esta bienal en su sexta edición del año 2007 al nombrar a Luis Camnitzer como curador pedagógico.

De esta forma, el escenario actual otorga a la función educativa un rol cada vez más importante en la diversa oferta cultural ofrecida por museos, centros culturales, bienales y otras instancias. Por lo tanto, este artículo se centrará en las dinámicas propias de los museos, opción basada en la consideración de estas instituciones como las garantes de procurar el acceso universal de todas las personas a su patrimonio:

Un museo es una institución permanente, sin fines de lucro, al servicio de la sociedad y abierta al público, que adquiere, conserva, estudia, expone y difunde el patrimonio material e inmaterial de la humanidad con fines de estudio, educación y recreo (ICOM, 2007).

Estas características hacen que los museos, a diferencia de otras instituciones culturales dedicadas al arte, tengan, implícita y de forma permanente, como misión acercar sus colecciones a diversos tipos de públicos que incluya a los visitantes escolares como uno de los más relevantes.

\section{Museos de Arte y escuela. Antecedentes respecto a la construcción de una alianza}

Los museos de arte han buscado brindar a los estudiantes la oportunidad de tener experiencias estéticas significativas con obras originales. Este es un punto no menor, ya que la falta de acceso a los museos continúa presente, pues existe en la ciudadanía la sensación de que son espacios elitistas. A esto se suma la necesidad de generar 
nuevas estrategias que consideren los desafíos propios de los museos de arte, ya que estos son más reticentes al uso de museografía didáctica, la cual permite reforzar aspectos clave de las obras.

Por lo general, los museos de arte utilizan el trabajo de un guía o educador que entrega las herramientas para abordar las obras y que ayuda a realizar las conexiones entre las experiencias previas que tienen los visitantes en torno al fenómeno artístico y la obra original que tienen la posibilidad de apreciar.

En cuanto a los escolares se refiere, la visita guiada se ha convertido en la actividad educativa por excelencia, la cual se encuentra en prácticamente todos los museos. Generalmente son realizadas por un educador y tienen como objetivo facilitar el diálogo entre la exposición y los estudiantes. De esta manera, el museo ayuda a los estudiantes tanto a la comprensión de las obras como a la ampliación de conocimientos sobre determinadas temáticas. Actualmente, se busca que los educadores motiven el diálogo y la participación colectiva para establecer nexos entre el mensaje expositivo y los conocimientos previos de los vistitantes.

Junto con este nuevo enfoque de las visitas que cambió los extensos monólogos de los guías por el trabajo recién mencionado de los educadores, los museos han generado estrategias que permiten conectar sus colecciones con el currículum escolar en el área de artes visuales. Esta conexión busca generar actividades que le den la posibilidad a los docentes de complementar los contenidos de su clase y no hacer de la visita un evento aislado.

Esta reflexión ha generado a partir de los años noventa en Latinoamérica un creciente interés por generar alianzas entre museo y escuela que intenten, mediante acciones conjuntas, realizar aportes a los ámbitos educativos formal y no formal respectivamente; sin embargo, tal como señalan Alderoqui y Pedersoli (2011), el escenario no es fácil, pues ambas instituciones tienen códigos propios y concepciones de la educación que no siempre propician un acercamiento fluido. Precisamente es en este último ámbito en donde se comienza a centrar el trabajo museo-escuela en nuestra región:

La sociedad cultura-educación provoca una demanda hacia las escuelas y hacia los museos para que busquen nuevos modos de alianza, que mejoren y pongan en valor los que ya existen. No estamos hablando aquí de la información de la oferta museal para las escuelas, que en función de los sofisticados medios tecnológicos puede llegar a ser abrumadora. Tampoco de las clásicas "visitas escolares" sueltas, que lo único que reproducen es la separación, la ausencia de proyecto, lo excepcional. No se trata de ver los museos como lugares de ilustración de lo enseñado. Se trata de generar acciones orientadas a la producción de una sociedad en donde cada uno tiene su propio objetivo, que se va cruzando con los objetivos del otro (Alderoqui y Pedersoli, 2011, p. 184) 
Este cruce al que se hace referencia adquiere diferentes matices según las instituciones -museo y escuela-y la praxis de los docentes de arte. Además, se suma a esto, las características del área de educación artística, en donde su relación con el museo cobra una mayor relevancia en cuanto son instancias fundamentales para el desarrollo de la apreciación estética.

Amaia Arriaga e Imanol Agirre (2010) investigaron respecto a las ideas del arte e interpretación que subyacen en la oferta educativa de los museos de arte mediante la identificación de cuatro formas de concebir y de interpretar las obras en el contexto de los programas educativos en museos. Estas concepciones son importantes a la hora de plantear el programa educativo y la posible sinergia con la educación artística en la escuela.

La primera concepción corresponde a la comprensión de la obra de arte como un acontecimiento y representación visual. En esta tendencia, la labor educativa se centra en el reconocimiento, descripción y valoración de los aspectos visibles de dicha obra. La segunda concepción valora el aspecto comunicativo de la obra de arte. Por dicha razón, la labor educativa se centra tanto en el mensaje de la obra que los asistentes deben develar como en lograr que los asistentes indaguen sobre los significados y/o los simbolismos presentes en las mismas. La tercera concepción incorpora a la obra de arte su componente histórico, cultural e intelectual, lo cual hace que los educadores se centren en una comprensión crítica del arte. Finalmente, se concibe la obra como la materialización de una experiencia, por lo cual la función educativa estará centrada en el visitante y sus experiencias como fuentes de significado.

A partir de las concepciones que se tiene en torno del arte, su potencial educativo y la manera de comprender al museo como institución pública, se articula, entonces, la forma en que se proyecta determinada oferta educativa que debe incluir la relación con los docentes, los recursos didácticos y otras iniciativas que desde el museo se generen.

Esto implica que, en primera instancia, el enfoque educativo del proyecto museal siempre estará determinado por la forma en que se comprende la educación desde el planteamiento del museo.

Puede decirse que recién cuando en un museo se plantean los problemas acerca de como los visitantes elijen su herencia y deja de pensarse en un primer término en las colecciones; cuando se pasa de un énfasis taxonómico a un énfasis explicativo, que acepta las ambigüedades y contradicciones, y comienza a intervenir el pensamiento cuestionador y crítico acerca del lugar que ocupan las voces del público como fuente de conocimiento en el desarrollo de las exposiciones es cuando su función educativa comienza a tener cierto espesor (Alderoqui y Pedersoli, 2011, p. 37). 
Esto se convierte actualmente en la columna vertebral de la función educativa del museo, ya que en una región como Latinoamérica, en donde escasean los recursos y muchas veces parte de los proyectos educativos se financian con base en fondos y no con presupuestos estables, es fundamental que se genere un posicionamiento desde la dirección del museo en torno a una función educativa que asuma tanto un modo de trabajo con la comunidad como un espacio que le otorge a los visitantes la posibilidad de realizar un trabajo colaborativo.

\section{Museos de Arte y su oferta educativa para la escuela}

Los museos han llevado a cabo diversas estrategias con el fin de acercarse a los docentes y establecer instancias de trabajo conjunto museo-escuela. En general, gran parte del acercamiento ha sido generado por los museos, o por investigadores ligados a estas instituciones, por el hecho de ser espacios con mayor flexibilidad para innovar en torno a propuestas didácticas. Esto se debe a que en la escuela aún se mantienen estructuras rígidas que limitan a los docentes para que puedan generar, desde el área de artes, proyectos para trabajar en conjunto con los museos.

Desde la década de los ochenta, se ha trabajado desde distintos frentes con el fin de abordar el problema de la visita descontextualizada al museo. A través del siguiente árbol de problemas se grafica este aspecto que durante bastante tiempo ha sido un tema central a la hora de investigar y generar proyectos que vinculen museo y escuela. 
Figura N. 1: Árbol de problemas. Relación Museo-Escuela

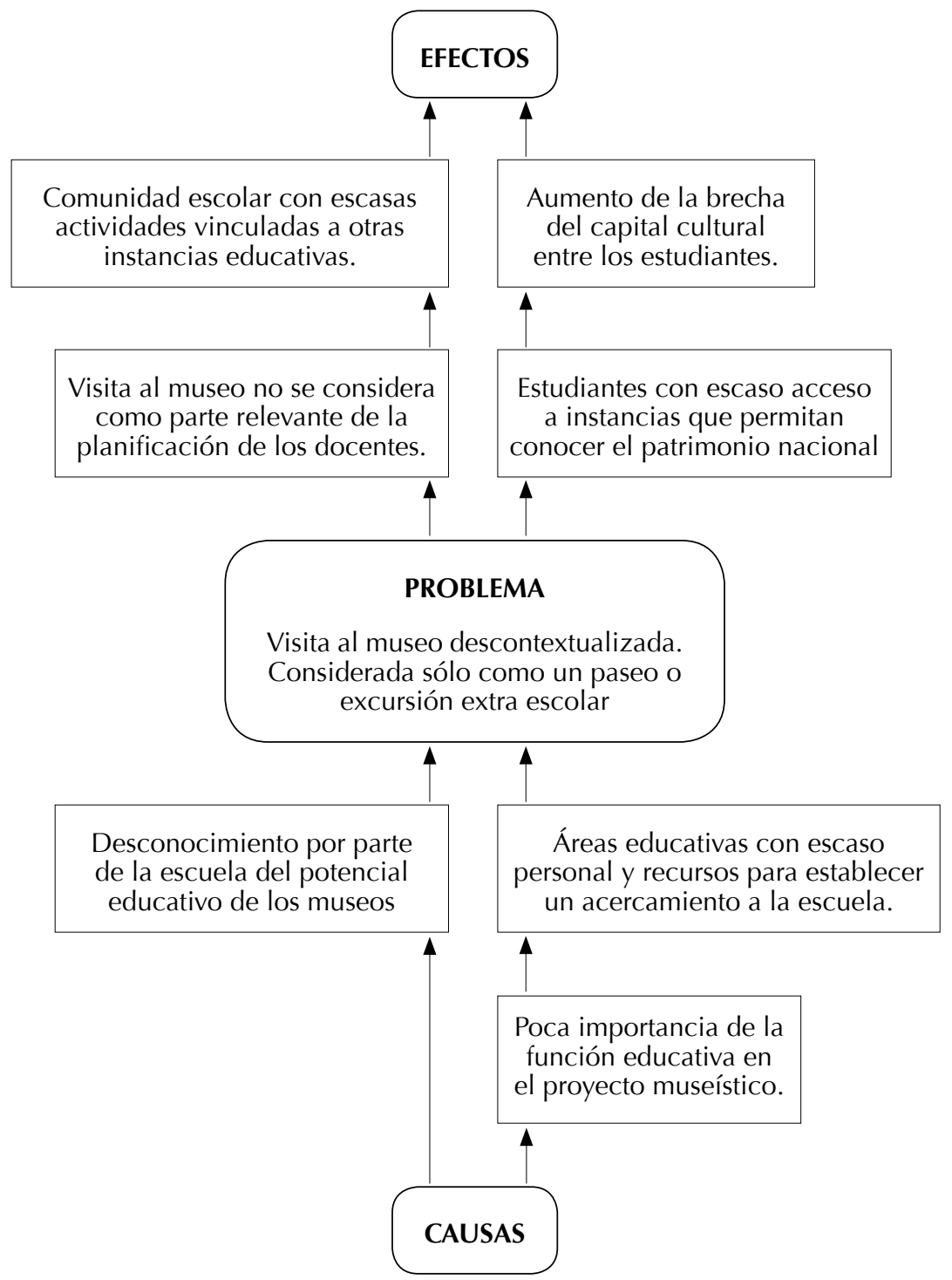

A partir de este escenario, diversas iniciativas han generado modelos sobre cómo sería más adecuado hacer este trabajo en conjunto. Uno muy interesante es el planteado por el grupo canadiense de investigación GREM —-Groupe de recherche sur l'éducation et les musées-, quienes según Rickenmann, Angulo y Soto (2011) han planteado un modelo inspirado en un progreso inductivo y en sintonía con el currículo escolar. 
[E]l proceso de aprendizaje en la base del modelo didáctico del grupo GREM comprende cuatro etapas de investigación a las cuales corresponden tres momentos de aprendizaje, a saber: la etapa de la exploración (también denominada etapa de interrogación) antes de la visita, la etapa de recolección de la información durante la visita y las etapas de análisis y síntesis después de la visita (2011, p 26).

Cada uno de los momentos que este método ha establecido busca que se generen procesos en miras a generar aprendizaje significativo para los estudiantes. En este sentido, se enfatiza que en las actividades previas a la visita, el docente debe estar involucrado en el asunto y otorgar a los estudiantes la información necesaria para aprovechar su visita al museo. Esta información debe incluir tanto aspectos prácticos, tales como qué es un museo y las funciones que cumple en la sociedad como aspectos específicos afines a los contenidos que se desarrollarán.

En el marco de la visita al museo, el método propone que se realicen algunas de las actividades que generalmente ofrecen los programas educativos al enfatizar en aspectos importantes para el disfrute de los estudiantes. Así mismo, en la visita no debe haber un exceso tanto en la cantidad de piezas e información incluidas en el itinerario como en el material complementario que se presenta. En definitiva, se debe comprender las características del espacio museal y la potencialidad que tiene como instancia no formal. Además, este espacio promueve que los estudiantes tengan una participación más activa al romper el protagonismo de los educadores en dicha instancia.

Finalmente, la última fase, posterior a la visita, se considera como un momento en donde el estudiante debería utilizar la información obtenida en el museo y profundizarla mediante la investigación para formular conclusiones propias, las cuales se deberían compartir y retroalimentar con sus compañeros.

En definitiva, varios puntos de la propuesta que este grupo de expertos ha elaborado son comunes a lo que algunos museos han generado de forma quizá más intuitiva, pero siempre con el fin de superar la noción de que la visita a los museos sea una excursión o paseo sin mayor transcendencia educativa.

Actualmente hay varias estrategias en esa línea, un número importante de museos en Latinoamérica ha optado por analizar sus colecciones y/o exposiciones al buscar puntos de conexión con el currículo para generar una oferta educativa en relación con los contenidos de la escuela en determinadas asignaturas.

Los museos de arte no han estado ajenos a este proceso de renovación de los enfoques educativos, pues realizan materiales y/o actividades en sintonía con algunos contenidos de la asignatura de artes visuales. 
El siguiente esquema resume algunas de las iniciativas que se realizan de forma más frecuente en los museos de arte con el fin de optimizar el proceso educativo en torno a la visita:

Figura N. $^{\circ}$ 2: Esquema de oferta educativa dirigida al público escolar

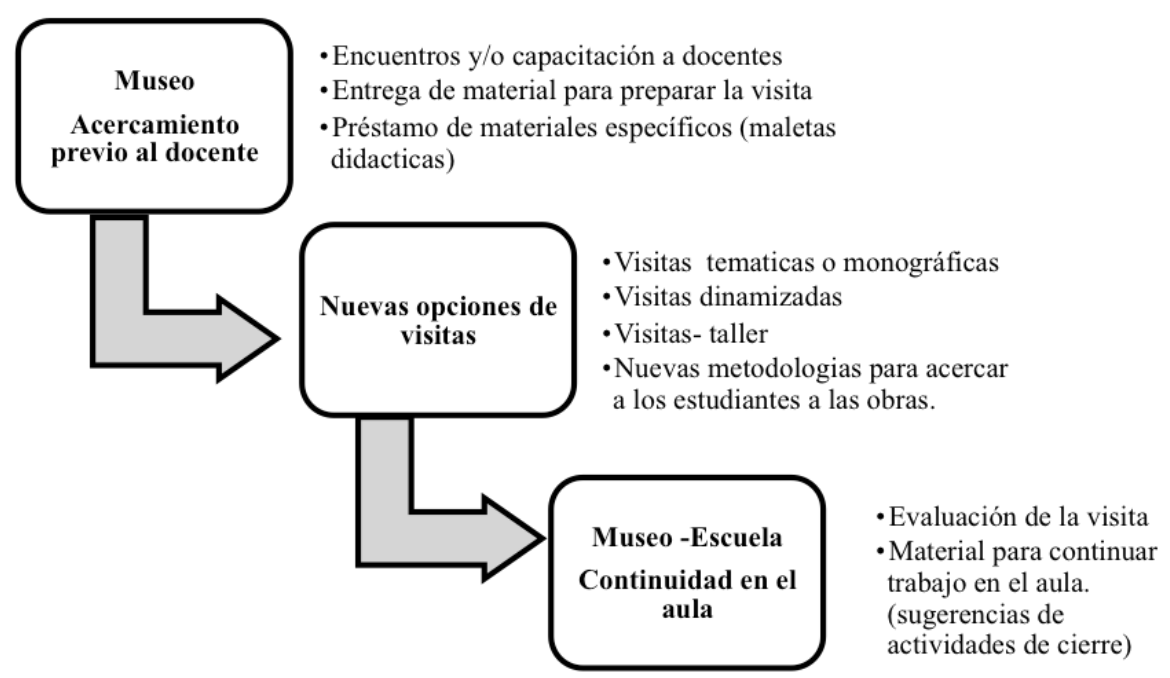

Lo primordial es comprender que en este proceso el museo tiene el potencial de ser una poderosa instancia de aprendizaje no formal en torno al arte que, si bien es de una naturaleza distinta a la de la escuela, permite lograr aprendizajes únicos al trabajar en forma conjunta.

Mikel Asencio y Elena Pol (2002) abordan la importancia que tiene en la formación de los estudiantes las instancias de aprendizaje no formal al señalar que en ocasiones este aprendizaje puede ser más consistente y significativo que el que se adquiere en el contexto escolar formal. Además, muestran que esto es posible, entre otras cosas, porque el aprendizaje que se logra en los contextos no formales, como los museos, puede lograr más cercanía al ser menos abstracto que el promovido por la escuela.

En este sentido, el trabajo conjunto puede traer grandes beneficios a la hora de optimizar las escasas horas de educación artística del currículum escolar. Para esto, es importante que esta instancia sea aprovechada al máximo por las dos instituciones, que sea planificada y que se adecue al contexto y las necesidades de los estudiantes. 


\section{Importancia del rol docente en la alianza museo-escuela. Algunas prácticas significativas}

Optimizar la visita a un museo o institución cultural implica la conexión previa entre ambas instituciones para crear un proceso educativo que trascienda la visita. En este sentido, el docente de la escuela es una figura fundamental, pues tiene la labor de que la conexión funcione mediante la continuidad que dé en clase a la experiencia vivida en el museo. Esto aún constituye un desafío, ya que si bien la diversificación de los programas para escolares en los museos denota que el interés en visitarlos va en aumento, es importante pensar qué tipo de visita se realiza, con qué intención y qué objetivo. Todos estos factores plantean un tema de fondo respecto al rol del museo en la tarea de revitalizar la educación artística.

El tema de la vinculación de profesores en Latinoamerica se vuelve un eje muy importante en la función educativa de los museos por dos razones. En primer lugar, la actividad de aquéllos es fundamental en cuanto son los encargados, la mayoría de las veces, de llevar por primera vez a los estudiantes al museo. En segundo lugar, porque pueden generar el concepto de ocio cultural en la sociedad con el fin de que el museo adquiera más relevancia en la región.

Debido a esto, algunos museos comenzaron a diseñar estrategias para que la visita sea exitosa y significativa para los estudiantes. Muchos incluyen la realización de material didáctico - fichas, maletas didácticas, vídeos, entre otros - que puedan ser utilizados en miras a articular la visita al museo con contenidos del currículum escolar.

En este ámbito, el trabajo que el Museo del Oro de Bogotá realiza desde 1996 es un excelente ejemplo que permite entender como la relación museo-docente evoluciona. Este museo parte por instaurar encuentros pre-visita con profesores que consisten en hacer un recorrido con la utilización del material diseñado por el museo — cartilla para profesores_- Posteriormente, éstos planifican un recorrido autónomo para realizar con sus estudiantes. Este proceso se dio bajo la premisa de que "el maestro es el mejor guía"; sin embargo, la inducción de una tarde no fue suficiente, puesto que los docentes no se sentían con el conocimiento para responder posibles preguntas de sus estudiantes sobre piezas específicas de la exposición.

Por dicha razón, el Museo del Oro desde el año 2000 cambió su proyecto educativo por el de animación pedagógica:

Las animaciones son eventos interactivos entre un público escolar y las exposiciones, alrededor de un tema particular, motivados y conducidos por el animador y el maestro, quien queda encargado de darles continuidad en clase. El animador no enseña: ayuda a descubrir, incita a aprender (Garzón, 2011, p. 149). 
Actualmente se convoca a los docentes para coordinar el tipo de recorrido que desean realizar con sus estudiantes. Dicha capacitación previa es un requisito para visitar el museo porque evita que el docente en su posterior visita y recorrido con sus estudiantes tenga dudas sobre la exposición.

En esta capacitación previa se accede a la oferta de variados temas para trabajar con los estudiantes: sociedades prehispánicas y su arte, el cuerpo como expresión cultural, el manejo prehispánico del medio ambiente, el trabajo de los metales y los animales míticos.

Junto con la elección del tema, los docentes conocen la propuesta educativa del museo y los materiales asociados a ella, pues tuvieron anteriormente la oportunidad de acceder a la metodología de animación pedagógica que posteriormente se utilizará con sus estudiantes para vivenciar el proceso de "sentir, conocer = aprender" que el Museo del Oro ha establecido como metodología de educación patrimonial.

Esta reflexión también ha alcanzado a otros museos que generan propuestas similares basadas en itinerarios. En esta línea se puede situar el trabajo que se realiza en el Museo Rafael Larco Herrera de Perú ${ }^{3}$, en donde se ofrecen diversos recorridos para educación primaria y secundaria, realizados por docentes-guías, profesionales nombrados de esta forma por el museo, y que son educadores con formación diversa y especifica en pedagogía museística e interpretación del patrimonio.

Las visitas para escolares que este museo ofrece actualmente se basan en diversos temas y programas, los cuales aportan y nutren a las diferentes asignaturas de la educación formal.

Cada programa está diseñado para motivar, acompañar y fortalecer el desarrollo de capacidades, habilidades y actitudes contempladas en la currícula de diversas áreas como Ciencias Sociales, Comunicación, Ciencia y Ambientes, Lógico-Matemática y Arte. Los programas buscan facilitar el conocimiento y la comprensión de las culturas del antiguo Perú en un ambiente de indagación, diálogo y cuestionamiento, reforzados por actividades interactivas (EducaLarco, 2016).

Actualmente los itinerarios ofrecidos por el Museo Rafael Larco Herrera son: biodiversidad: alimentos y animales del antiguo Perú, mitos y rituales en la cultura mochica, "un detective en el museo", animales sagrados, dualidad en el antiguo Perú y los incas: la construcción de un imperio.

Dichos recorridos también dan la opción a los docentes de acceder a material preparado por el museo que incluye actividades pre y post visita con el fin de asegurar el proceso educativo y la continuidad en el aula de la experiencia.

3 Para mayor información sobre el museo y los programas educativos visitar: www.museolarco.org. 
Sin embargo, existen otros museos que han planteado preguntas respecto a cuál es realmente su función en torno a la vinculación con la educación formal: ¿idebe el museo hacer un trabajo dirigido a la escuela, estudiar el currículum y promover actividades en esa línea al considerar que gran parte de sus visitantes son escolares? ¿El museo debe empoderar al docente para que realice sus propias conexiones? El debate actual se comienza a centrar en las diversas formas en que se puede establecer una relación entre museo y escuela.

También hay museos que no se responsabilizan por aportar a la educación escolar de forma dirigida, pues no le entregan a los docentes una capacitación o materiales específicos, sino que centran su apuesta en otorgar una formación mucho más flexible, con el fin de que sean ellos quienes, al conocer el contexto donde trabajan, determinen que se debe realizar para optimizar la visita.

Un ejemplo de esto es el Museo Nacional de Bellas Artes —MNBA— de Chile que a través de sus cursos para docentes busca otorgarles herramientas para que puedan hacer sus propias lecturas críticas de la colección y generar propuestas educativas para sus estudiantes.

Fruto de este trabajo, han surgido dos publicaciones del área educativa de este museo que abordan esta temática. En estas publicaciones entregan su postura como museo nacional sobre el proceso de empoderamiento que desean realizar con los profesores.

Respecto a esto Natalia Portugueis (2014), coordinadora del área de mediación y educación del MNBA, señala que:

[N]os propusimos no trabajar con guiones establecidos ni guías de trabajo sincrónicas al programa escolar, para no replicar el trabajo de la educación formal en un espacio no formal, sino que hacer un aporte desde ese lugar de libertad y enriquecimiento, propio del arte y que en una institución como el museo, se da con facilidad. Me refiero al diálogo, a la participación, a que los y las estudiantes sientan, experimenten y se relacionen con el arte como sujetos activos, opinantes, libres de toda evaluación de su actuar (p. 16).

Figura N. ${ }^{\circ}$ 3: Publicaciones del Museo Nacional de Bellas Artes, Santiago, Chile. Ambas referidas al trabajo Museo- Docentes realizado durante el periodo 2013-2015.

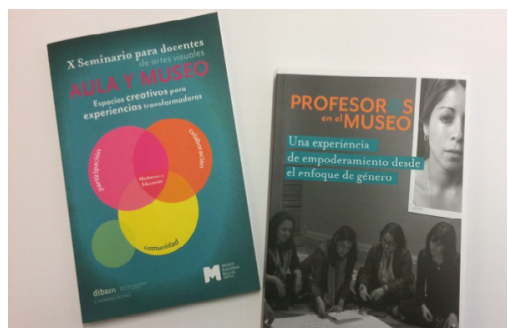


También en Chile, el Museo de la Solidaridad Salvador Allende opta por alejarse de la oferta articulada con el currículo y generar un programa educativo acorde a las características del museo ${ }^{4}$ y sus visitantes. Desde el área de públicos del museo, Fernández, Molina y Sánchez (2014) reflexionan en torno al proceso vivido al intentar realizar actividades en línea con el currículo nacional:

[c]uando fueron elaboradas las primeras planificaciones para las actividades se utilizaron los objetivos planteados en los Planes y Programas de Arte Visuales e Historia. Esto generó dificultades prácticas y metodológicas, ya que el cruce forzoso entre los contenidos y objeti vos del currículum y los propios del museo, finalmente, sacrificaba potenciar las posibilidades de aprendizaje propias de los espacios no formales, sin contribuir necesariamente a fortalecer las del currículum (p. 147).

De esta forma, el museo comienza a explorar otras metodologías que articulan una oferta basada en la mediación artística y en la importancia de fortalecer lo que consideran es propio del espacio museal. De esta manera, buscan generar experiencias basadas en el diálogo, la experimentación y la reflexión individual y colectiva.

De la misma manera, no se crean recursos específicos para docentes ni actividades en línea con ninguna asignatura, sino que se articulan tres ejes flexibles desde donde el museo propone trabajar en sus diferentes actividades: colección MSSA; problemas del arte contemporáneo; y patrimonio y memoria.

Otra forma de acercar a los museos y a las escuelas es mediante la generación de procesos más complejos que permitan a las escuelas reflexionar e implementar un proyecto educativo en donde pueda definirse de forma más clara el enfoque que se le otorgará a la enseñanza artística en el contexto escolar.

Un ejemplo es el convenio que han establecido el MAVI —Museo de Artes Visuales de Santiago de Chile—y la Fundación Belén Educa ${ }^{6}$ — Red de colegios de la misma ciudad - en donde se han realizado distintas actividades que incluyen las visitas de cursos de la Red de colegios al mavı y también la participación de los docentes de arte en laboratorios con artistas y otras actividades de creación y reflexión en torno a las artes visuales.

4 El MSSA es un museo del arte ubicado en la ciudad de Santiago que posee una colección de arte moderno y contemporáneo de aproximadamente 2800 obras. Esta colección fue posible por donaciones de artistas que se solidarizan con el proyecto político del presidente Salvador Allende. Para más información sobre la colección, historia y características de este museo visitar: http://www. mssa.cl

5 Para mayor información en torno al museo visitar: www.mavi.cl

6 Para mayor información sobre la Fundación Belén Educa y su Red de colegios visitar: www. beleneduca.cl 
Además, el museo elabora fichas didácticas y otros recursos para que los docentes puedan profundizar el trabajo en clases. En este marco, se establece un trabajo conjunto entre el museo y la escuela que conecta el material elaborado con el currículo., Además, se constituye una red de colaboración que permanece en el tiempo, pues el personal del museo trabaja durante todo el año con el equipo docente de la institución educativa.

\section{Conclusiones}

A través de estos ejemplos se puede notar un panorama heterogéneo sobre el convenio museo-escuela. Existen diversas formas de relacionar el museo con el colectivo docente; sin embargo, aunque todas las opciones son válidas y valorables, es fundamental enfatizar que los profesores de arte deben tener un rol protagónico en el proceso de visita a museos, pues se pueden correr varios riesgos en este convenio. Por ejemplo, uno de los riesgos del creciente trabajo educativo de los museos es que en la preparación de material e itinerarios para los grupos escolares se entreguen productos prediseñados que pueden resultar carentes de sentido para los estudiantes.

Junto con esto es importante que los docentes tomen una posición respecto a los nuevos enfoques de las visitas a museos de arte, dentro de las cuales aún se encuentran propuestas basadas en visitas tanto guiadas como expositivas, en donde se entrega información y contenidos en torno al arte. También, se encuentran visitas con un enfoque más lúdico en donde los educadores, utilizan estrategias de animación sociocultural para generar conocimiento. Finalmente, se encuentran propuestas de mediación en donde se replantea la forma en que se comprende la función educativa del museo.

Este último aspecto es parte importante del escenario actual, pues existen propuestas en miras a superar las dos funciones dominantes en la educación museal, a saber, la afirmativa y la reproductiva. Estas propuestas, según Carmen Mörsch, se dan con mayor frecuencia e instalan una función educativa en donde el museo sólo comunica el discurso ya establecido sin brindar un espacio para problematizarlo. Así pues, estas nociones están muy arraigadas en gran parte de los museos y forman parte del imaginario que los docentes y estudiantes tienen sobre el rol educativo de estas instituciones.

Todo lo contrario, se propone en la mediación que busca pasar a las funciones reconstructivas y transformativas que confieren al espacio museal una permeabilidad en donde los visitantes no sólo son los receptores de determinadas iniciativas, sino quienes pueden reconstruirlas tanto al valorar la dimensión política del museo como al hacer posible el trabajo en red que plantea la museología crítica. Como afirma Javier Rodrigo (2012), en esta mediación cambia la relación vertical entre el museo y los visitantes, pues ésta se transforma en un trabajo colaborativo que considera al 
museo no como un foco centralizador y generador de cultura, sino como un agente que se involucra dentro de estos procesos.

Es importante, entonces, que estas nociones que se teorizan desde la museología tengan eco en los docentes. De esta manera, ellos podrán elegir cuál es el proyecto que se relaciona mejor con las características del trabajo que quieren realizar con los estudiantes. Así mismo, estas nociones deben jugar un papel fundamental dentro del debate para elegir las estrategias más significativas que consideren el contexto actual de la educación artística en la escuela.

De esta forma, se puede concluir que se ha generado un momento fructífero para la educación en museos de arte mediante la implementación de recursos, investigaciones y debates en torno a las mejores formas de optimizar la relación museo-escuela. Este ambiente constituye un escenario favorable con múltiples oportunidades para abordar aspectos relevantes de la educación artística que fortalezcan la idea de que la enseñanza de las artes visuales es un campo de estudio consistente e importante en las discusiones de educación que afectan el continente. 


\section{Referencias}

Alderoqui, S., y Pedersoli, C. (2011). La educación en los Museos. De los objetos a los visitantes. Buenos Aires, Paidós.

Amaia, A., y Agirre, I. (2010) Un aparato metodológico para analizar las ideas de arte e interpretación que subyacen en discursos y prácticas educativas de museos de arte. En Revista Iberoamericana de educación, 53, 203-223.

Ascencio, M., y Pol, E. (2002). Nuevos escenarios en Educación. Buenos Aires: Aique.

Fernández, C., Molina, A., y Sánchez, S. (2014). “Actividades en el MSSA: vivenciar e interpretar nuestro patrimonio" En Actas V Congreso de Educación, Museos y Patrimonio. Santiago: Ediciones DIBAM.

Garzón, F. (2011). "Disfrutar, enseñar o estimular los procesos de comprensión en los museos". En CeCA., DibAM., ICOM, Actas IV Congreso de Educación, Museos y Patrimonio. Santiago de Chile: Ediciones DIBAM.

Mörsch, C. (2011). Entrevista a Carmen Mörsch. Por Diego del Pozo y Virginia Villaplana. En Revista Arte y Políticas de Identidad. Universidad de Murcia, 4, 203-224.

Mörsch, C. (2012). Contradecirse uno mismo: la educación en museos y exposiciones como práctica crítica. En Transductores. Pedagogías en red y prácticas instituyentes. Granada: Ediciones Centro José Guerrero.

Pastor, M. (2001). "Orígenes y evolución del concepto de educación no formal". Revista Española de pedagogía, 69(220), 525-544.

Portugueis, N. (2014) "El mNBA y la educación no formal en artes visuales". En Aula y Museo. Espacios creativos para experiencias transformadoras. Santiago de Chile: Ediciones Dibam.

Rikenmann, R., Angulo, F. y Soto, C. (2011). El Museo como medio didáctico. Bogotá: Ediciones Siglo del Hombre.

Rodrigo, J. (2012). Experiencias de mediación crítica y trabajo en red en museos. En Revista Museos, 31, 74-85

Recibido: 13 de enero 2016

Aceptado: 11 marzo 2016

Cómo citar: Miralles, N. (2016). Educación artística en museos:

sinergia entre aula y museo. Actualidad y desafíos en la construcción de una alianza. Praxis Pedagógica, 19, 43-59 